\title{
Degradability of cross-linked polyurethanes based on synthetic polyhydroxybutyrate and modified with polylactide
}

\author{
Joanna Brzeska ${ }^{1} \cdot$ Magda Morawska $^{1}$ - Wanda Sikorska ${ }^{2}$ Agnieszka Tercjak ${ }^{3}$. \\ Marek Kowalczuk $^{2,4} \cdot$ Maria Rutkowska $^{1}$
}

Received: 3 February 2017/Accepted: 2 June 2017/Published online: 14 June 2017

(c) The Author(s) 2017. This article is an open access publication

\begin{abstract}
In many areas of application of conventional non-degradable cross-linked polyurethanes (PUR), there is a need for their degradation under the influence of specific environmental factors. It is practiced by incorporation of sensitive to degradation compounds (usually of natural origin) into the polyurethane structure, or by mixing them with polyurethanes. Cross-linked polyurethanes (with 10 and 30\%wt amount of synthetic poly([R,S]-3-hydroxybutyrate) (R,S-PHB) in soft segments) and their physical blends with poly([D,L]-lactide) (PDLLA) were investigated and then degraded under hydrolytic (phosphate buffer solution) and oxidative $\left(\mathrm{CoCl}_{2} / \mathrm{H}_{2} \mathrm{O}_{2}\right)$ conditions. The rate of degradation was monitored by changes of samples mass, morphology of surface and their thermal properties. Despite the small weight losses of samples, the changes of thermal properties of polymers and topography of their surface indicated that they were susceptible to gradual degradation under oxidative and hydrolytic conditions. Blends of PDLLA and polyurethane with $30 \mathrm{wt} \%$ of $R, S$ -
\end{abstract}

Joanna Brzeska

j.brzeska@wpit.am.gdynia.pl

1 Department of Commodity Industrial Science and Chemistry, Gdynia Maritime University, 83 Morska Street, 81-225 Gdynia, Poland

2 Centre of Polymer and Carbon Materials, Polish Academy of Sciences, 34 Sklodowska-Curie Street, 41-819 Zabrze, Poland

3 Group 'Materials+Technologies' (GMT), Department of Chemical and Environmental Engineering, University of the Basque Country (UPV/EHU), Plaza Europa 1, 20018 Donostia-San Sebastián, Spain

4 School of Biology, Chemistry and Forensic Science, Faculty of Science and Engineering, University of Wolverhampton, Wolverhampton WV1 1SB, UK
PHB in soft segments and PUR/PDLLA blends absorbed morewater and degraded faster than polyurethane with low amount of $R, S$-PHB.

Keywords Degradable polymers · Cross-linked polyurethanes - Synthetic polyhydroxybutyrate $\cdot$ Polymer blends Polylactide

\section{Introduction}

Last decades have brought a significant increase in the amount and kind of renewable substrates used to obtain polyurethanes (PUR). Use of natural materials is one of the methods of making polyurethane materials more biocompatible and biodegradable. Cross-linked polyurethanes are modified chemically by introducing bio-based substrates, such as: saccharides (Okoli et al. 2014; Zia et al. 2016a), oils (Arniza et al. 2015; Ionescu et al. 2016), bio-based polyesters (Zhang et al. 2015), and others (Silva et al. 2009; Datta and Głowińska 2014) into the PUR structure. Properties of polyurethanes can be also modified by physical blending of linear and cross-linked PUR with compounds existing in nature or obtained by the biosynthesis, like peptides (Zuber et al. 2015), polysaccharides (Saralegi et al. 2014; Zia et al. 2016b; Brzeska et al. 2015a) and polyhydroxyalkanoates (Martínez-Abad et al. 2016).

Introducing bio-compounds into the polyurethane structure allowed naming it as bio-polyurethane, whereas mixing polyurethane with natural material-as bio-composite (or bio-blend) (Aranguren et al. 2015). Degradable polyurethanes (linear and cross-linked) can be also obtained from chemically synthesized degradable substrates, e.g., synthetic poly([R,S]-3-hydroxybutyrate) (R,SPHB) (Brzeska et al. 2015b, 2016). R,S-PHB is synthesized 
by anionic ring opening polymerization of B-butyrolactone and it is a promising substrate for degradable materials. Its amorphous character Amorphousness and the presence of its monomers in nature make the $R, S$-PHB susceptible to degradation under natural conditions.

Polylactide-based polymers are commonly used as degradable material for packaging and medical applications, because they are degradable and bioassimilated in a human body and in the natural environment (Vert 2015). Hydrolysis is the main pathway of polylactide (PLA) degradation. Degradation of ester moiety in aqueous medium leads to the formation of carboxyl and hydroxyl hydrophilic end groups. The rate of degradation depends on the polymer character and structure, and thus on the ease of penetration of water into the polymer network. Amorphous, hydrophilic polymer with low molecular weight and density is degraded faster than that which is crystalline, hydrophobic and with high molecular weight and density.

Properties of PLA are strictly connected with its stereoregularity (Nampoothiri et al. 2010). PLA homopolymers (based only on L-lactide or D-lactide) are semi-crystalline polyesters, whereas meso-lactide (D,L-lactide) and racemic-

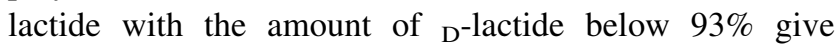
amorphous PLA materials (Raquez et al. 2013).

Kinetics of polymer degradation is affected both by the environment conditions and by the polymer structure and their physical properties. Properties and degradability of physical blends of linear polyurethanes and polylactide are quite often investigated (Imre et al. 2013; Brzeska et al. 2015c; Jašo et al. 2015; Yu and Huang 2015; Jing et al. 2015), especially with reference to their potential usability for medical applications (Grzesiak et al. 2015; Saini et al. 2016). Whereas, blends of cross-linked polyurethane with polylactide are tested much less frequently (Gurunathan et al. 2014).

In this paper, the influence of structure, density and swelling of cross-linked polyurethanes (based on synthetic $\mathrm{R}, \mathrm{S}-\mathrm{PHB})$ on degradability of their blends with poly([D,L]lactide) (PDLLA) in hydrolytic and oxidative solutions is presented.

\section{Experimental}

\section{Materials}

R,S-PHB was obtained by anionic ring opening polymerization of $\beta$-butyrolactone initiated by 3-hydroxybutyric acid sodium salt/18-crown-6 complex at room temperature and terminated with 2-bromoethanol (Arslan et al. 1999). Before the synthesis of polyurethanes, oligomeroles of R,SPHB $\left(M_{\mathrm{n}} 1700\right)$ and $\mathrm{PCL}_{\text {triol }}\left(M_{\mathrm{n}} 900\right.$, Aldrich) were dried by heating at $60-65^{\circ} \mathrm{C}$ under reduced pressure $(1.4 \mathrm{hPa})$. Other reagents were previously purified: 4,4'-methylene dicyclohexyl diisocyanate $\left(\mathrm{H}_{12} \mathrm{MDI}\right)$ (Alfa Aesar) was vacuum distilled, whereas chain extender 1,4-butanediol (1,4-BD) (Aldrich) was distilled azeotropically with benzene. Solvent $N, N$-dimethylformamide (DMF) (Labscan Ltd) was dehydrated over diphosphorous pentoxide $\left(\mathrm{P}_{2} \mathrm{O}_{5}\right)$ and distilled under low pressure before the synthesis. Catalyst: $\operatorname{tin}(\mathrm{II})$ octanoate $\left(\mathrm{Sn}(\mathrm{Oct})_{2}\right)$ (Akra Chem.) was used as received.

The synthesis of polyurethanes was carried out in a two-step reaction (as showed in Scheme 1), with the molar ratio of $\mathrm{NCO}: \mathrm{OH}=4: 1$ in the prepolymer step (Brzeska et al. 2017). Prepolymer of polyurethanes was synthesized for $3 \mathrm{~h}$ at $70-75^{\circ} \mathrm{C}$ under vacuum with mixed oligomeroles (in the weight ratio of $\mathrm{R}, \mathrm{S}$ PHB:PCL $\mathrm{P}_{\text {triol }}=10: 90$ or 30:70) and $\mathrm{H}_{12} \mathrm{MDI}$. NCO-terminated prepolymer was dissolved in DMF, and next its molecular weight was increased by reaction with chain extender (1,4-BD) for $2 \mathrm{~h}$ at $60^{\circ} \mathrm{C}$. Before pouring the polyurethane solution on Teflon plates it was blended with poly([D,L]-lactide $)\left(M_{\mathrm{w}} \quad 18,000-28,000\right.$, Aldrich $)$ dissolved in DMF. Blend foils were formed by heating at 80-105 ${ }^{\circ} \mathrm{C}$ in the vacuum heater for $6 \mathrm{~h}$.

Polyurethanes (non-blended with PDLLA) were also synthesized and investigated to estimate of PDLLA influence on their properties.

\section{Methods}

\section{Differential scanning calorimetry (DSC)}

Thermal properties of polyurethanes and their blends were determined using the Setaram thermal analyzer. Indium and lead were used for calibration. The specimens were sealed in aluminum pans and scanned from 20 to $200{ }^{\circ} \mathrm{C}$ with the heating rate of $10{ }^{\circ} \mathrm{C} / \mathrm{min}$. All experiments were made in a flow of dry $\mathrm{N}_{2}$. The melting temperatures $\left(\Delta T_{\mathrm{m}}\right)$ were determined as a minimum of melting endotherms whereas the melting enthalpies $\left(\Delta H_{\mathrm{m}}\right)$ were done by integrating the melting peaks on DSC curves.

Morphology of polymer surface was investigated by atomic force microscopy (AFM). AFM images were obtained operating in tapping mode (TM-AFM) with a scanning probe microscope (Dimension ICON Bruker) equipped with an integrated silicon tip/cantilever having a resonance frequency $\sim 300 \mathrm{kHz}$. Taken into account the similarity between height and phase AFM images, only AFM-phase images are shown here. The average roughness $\left(R_{\mathrm{a}}\right)$ was calculated using height AFM images. The roughness values for each investigated sample were taken from three independent areas. 


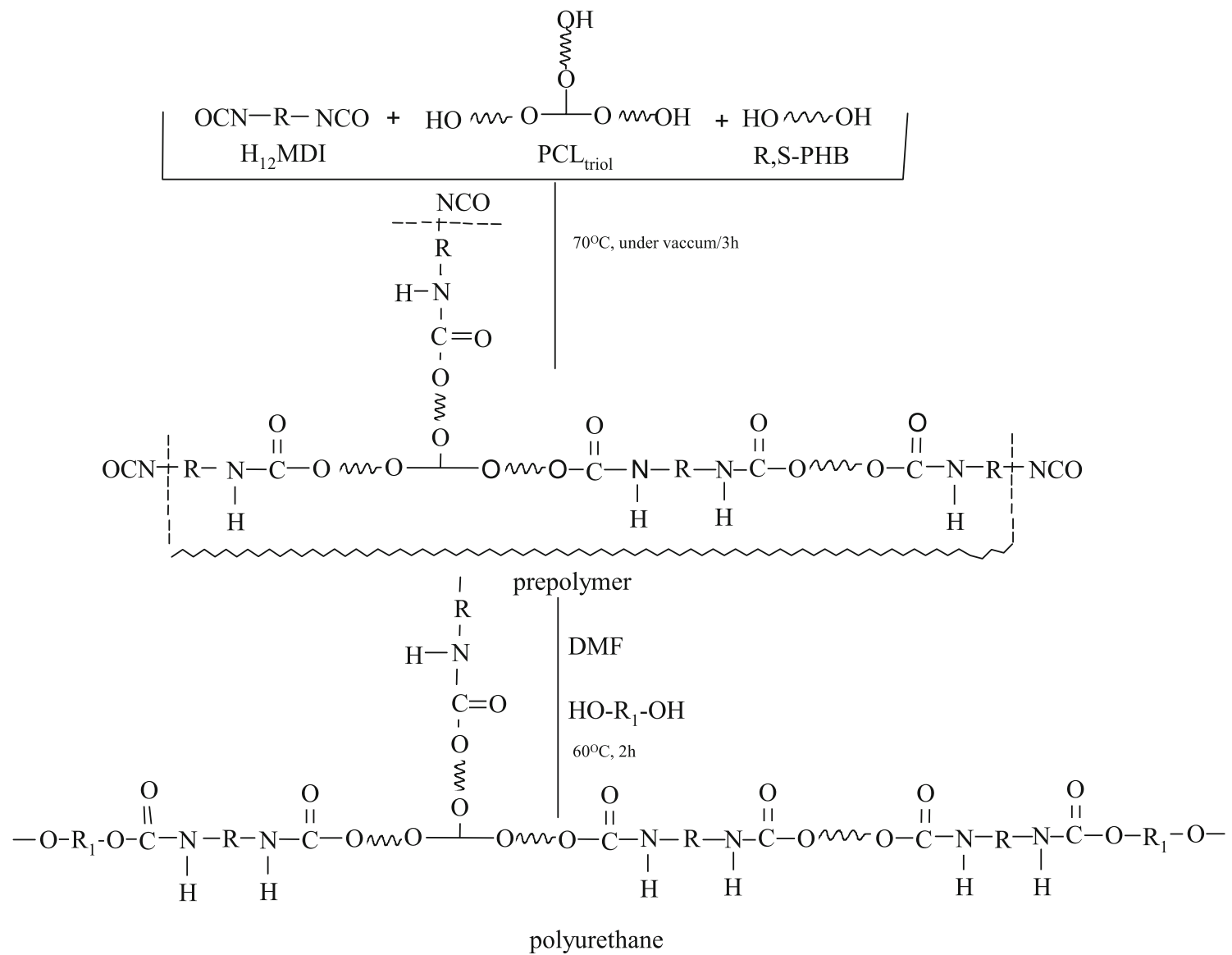

Scheme 1 Scheme of PUR preparation

\section{Density}

Density of polyurethanes was estimated using analytical balance equipped with the density determination kit. The measurements were repeated five times for each polymer.

\section{Oil and water sorption}

Polyurethanes and blends samples were immersed in sunflower oil at $37^{\circ} \mathrm{C}$ for $24 \mathrm{~h}$ and next they were weighed after wiping from the oil with filter paper (Szelest-Lewandowska et al. 2002). For water sorption estimation, the investigated polymers were immersed in deionized water for 14 days at $37^{\circ} \mathrm{C}$. Next the swollen samples were gently blotted with filter paper and weighed.

\section{Swelling}

Swelling of polyurethanes and their blends was determined in chloroform $\left(\mathrm{CHCl}_{3}\right)$. Samples $\left(1 \mathrm{~cm}^{2}\right)$ were immersed in $\mathrm{CHCl}_{3}$ at room temperature. After $24 \mathrm{~h}$, the swollen sample was weighed directly after gently blotted with filter paper.
Oil and water sorption and swelling in chloroform were calculated from the weight after incubation $\left(w_{i}\right)$ and the initial weight $\left(w_{0}\right)$ by:

Sorption $\%=\left(w_{i}-w_{0}\right) / w_{0} \times 100 \%$. The results were the average of three measurements.

\section{Degradation in buffer solution (PBS)}

Hydrolytic degradation of polyurethanes and their blends was carried out for 4, 12, 24 and 36 weeks, using the phosphate buffer solution ( $\mathrm{PBS}, \mathrm{pH}=7.01)$, containing sodium azide $(0.02 \%)$ as the bacteriostatic agent. The $\mathrm{pH}$ of the aging medium was checked every 2 weeks and the solution was replaced if the $\mathrm{pH}$ had changed by more than 0.5 (Glarner and Gogolewski 2007).

\section{Degradation in oxidative solution $(O X)$}

Oxidative degradation of polyurethane samples was carried out for 2, 4, 12 and 16 weeks, using the oxidative solution of $20 \% \mathrm{w} / \mathrm{w}$ hydrogen peroxide in the $0.1 \mathrm{M}$ cobalt chloride solution. The solution was changed every week to maintain constant concentration of radicals. One week was 
selected as an appropriate interval to replace the solution since the half-life of hydrogen peroxide at $37{ }^{\circ} \mathrm{C}$ was measured to be about 7 days (Feng and Li 2006).

The progress of degradation of the samples in both environments was monitored by observing changes in their mass, the surface morphology and in thermal properties.

\section{Results and discussion}

Two cross-linked polyurethanes were synthesized as shown in Scheme 1.

Polyurethanes were named according to the percentage of R,S-PHB in the soft segments, which was 10 and $30 \%$ by weight for PUR10 and PUR30, respectively.

The nomenclature and composition of polyurethanes and their blends with polylactide are presented in Table 1 .

The weight ratio of hard to soft segments in both polyurethanes was similar. They were only differed in amount of R,S-PHB and PCL $_{\text {triol }}$ in soft segments.

Density and swelling of polyurethanes and their blends with polylactide in vegetable oil and in chloroform are presented in Table 2.

Density of the obtained polyurethanes did not exceed the value $1.07 \mathrm{~g} / \mathrm{cm}^{2}$ (Table 2). It is known that the presence of cross-links in the polymers structure reduces mobility of macrochains, and restrains their interchain reactions (connected mainly with creation of hydrogen bonds), what decreases the polymer density. Blending polyurethanes with PDLLA increased the mobility of chains and allowed on their better packing which was the reason of density rise. An increase of density after PURs blending with PDLLA simultaneously reduced chloroform swelling (Table 2). Despite of high swelling of samples in

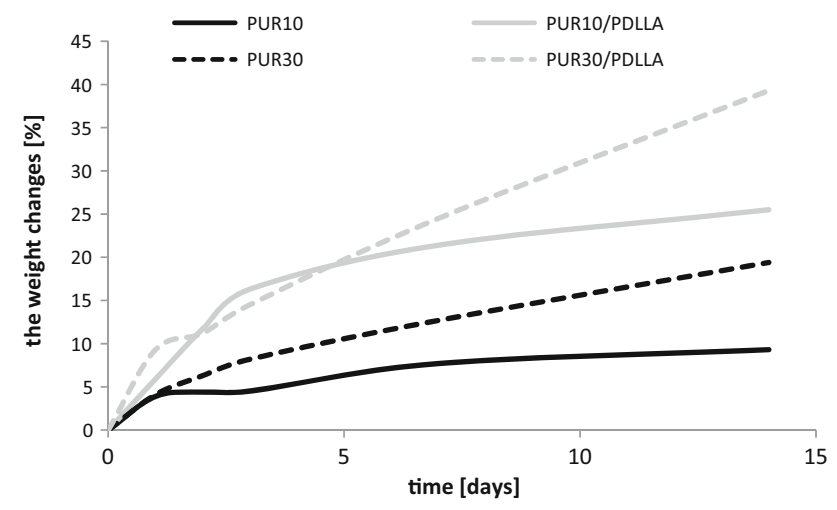

Fig. 1 Water sorption by cross-linked polyurethanes and their blends with PDLLA. Data for PUR10 and PUR30 presented in (Brzeska et al.2017)

chloroform cross-linked polyurethanes and their blends absorbed very low amount of vegetable oil (Table 2). High viscosity of oil medium restricted its uptake into crosslinked network of polyurethanes. Much higher swelling of polyurethanes in small molecules solvents (chloroform and toluene) in compare to edible oils absorption was also noted by Zhang et al. (2017).

Environmental degradability of polymers is mainly affected by water (often containing degradative compounds) availability and by easy water molecules migration into the polymer structure. The presence of cross-links in the polymers network generally significantly reduces water penetration that is generally one of the reasons of lower degradability of cross-linked than linear polyurethanes.

The synthetized polyurethanes and their blends were incubated in water for 14 days. In the case of samples with higher amount of R,S-PHB in soft segments (PUR30 and PUR30/PDLLA) the water sorption increased gradually in

Table 1 Name and composition (with wt\% of substrates in total mass) of polyurethanes and their blends with polylactide

\begin{tabular}{|c|c|c|c|c|c|}
\hline \multirow[t]{2}{*}{ Sample } & \multicolumn{2}{|c|}{ Substrates used for soft segments building (wt\%) } & \multicolumn{2}{|c|}{ Substrates used for hard segments building (wt\%) } & \multirow{2}{*}{$\begin{array}{l}\text { Amount of PDLLA } \\
\text { in blend (wt } \%)\end{array}$} \\
\hline & R,S-PHB & $\mathrm{PCL}_{\text {triol }}$ & $\mathrm{H}_{12} \mathrm{MDI}$ & $1,4-\mathrm{BD}$ & \\
\hline PUR10 & 3.3 & 29.3 & 53.6 & 13.6 & 0 \\
\hline \multicolumn{5}{|c|}{ PUR10/PDLLA } & 5 \\
\hline PUR30 & 10.7 & 24.8 & 51.4 & 13.1 & 0 \\
\hline \multicolumn{5}{|c|}{ PUR30/PDLLA } & 5 \\
\hline
\end{tabular}

Table 2 Density and swelling in oil ad chloroform ( \pm standard deviation, SD) of polyurethanes and their blends with polylactide

\begin{tabular}{llll}
\hline Sample & $\begin{array}{l}\text { Density }( \pm \mathrm{SD}) \\
{\left[\mathrm{g} / \mathrm{cm}^{2}\right]}\end{array}$ & $\begin{array}{l}\text { Oil sorption }( \pm \mathrm{SD}) \\
{[\mathrm{wt} \%]}\end{array}$ & $\begin{array}{l}\text { Degree of swelling } \\
\text { in } \mathrm{CHCl}_{3}( \pm \mathrm{SD}) \\
{[\mathrm{wt} \%]}\end{array}$ \\
\hline PUR10 & $1.07 \pm 0.03^{*}$ & $0.5 \pm 0.1^{*}$ & $573 \pm 68$ \\
PUR10/PDLLA & $1.10 \pm 0.04$ & $1.0 \pm 0.4$ & $348 \pm 23$ \\
PUR30 & $1.06 \pm 0.03^{*}$ & $0.7 \pm 0.1^{*}$ & $842 \pm 101$ \\
PUR30/PDLLA & $1.09 \pm 0.01$ & $1.5 \pm 0.1$ & $97 \pm 13$ \\
\hline
\end{tabular}

* Data presented in (Brzeska et al. 2017) 


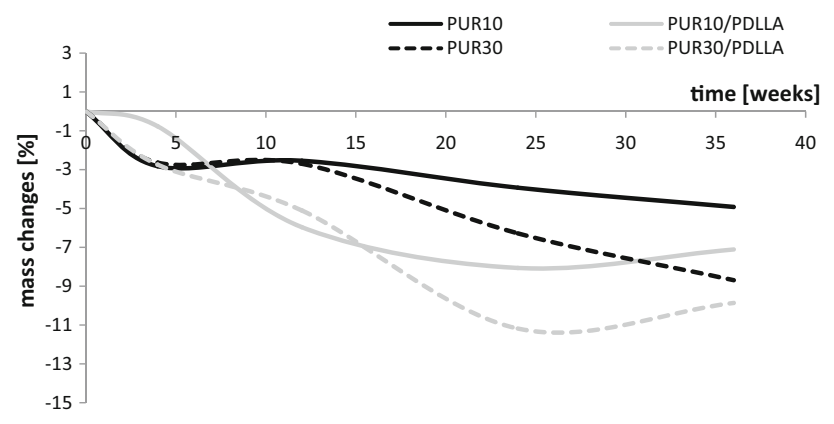

Fig. 2 Weight changes of PURs and their blends with PDLLA after incubation in the buffer solution. Data for PUR10 and PUR30 presented in (Brzeska et al.2017)

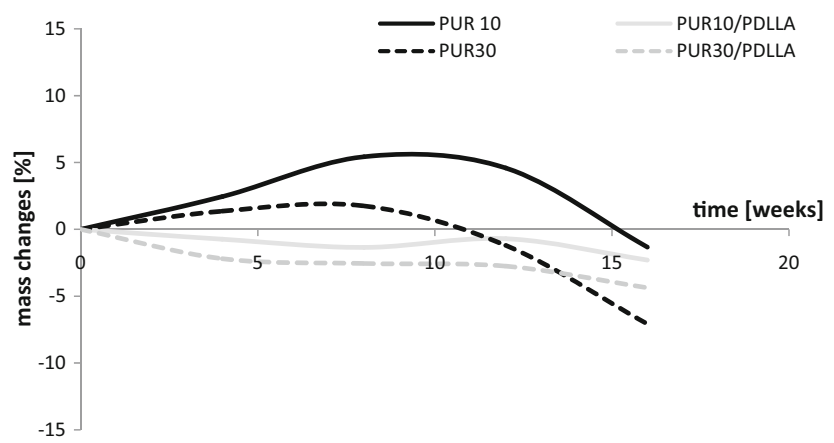

Fig. 3 Weight changes of PURs and their blends with PDLLA after incubation in oxidative solutions. Data for PUR10 and PUR30 presented in (Brzeska et al. 2017) time and they did not achieve the visible level of saturation (Fig. 1). Using the higher amount of R,S-PHB for the polyurethane synthesis and blending with PDLLA significantly increased sorption of water by samples. Increasing hydrophilicity of linear polyesterurethanes after introducing R,S-PHB into their structure was described in previous papers (Brzeska et al. 2015c). Moreover for both blends: PUR10/PDLLA and PUR30/PDLLA adding a second component-PDLLA-resulted in higher water sorption in comparison to native PUR10 and PUR30.

The weight changes of samples of polyurethanes and their blends after incubation in the buffer solution are reported in Fig. 2, and after incubation in oxidative solution-in Fig. 3.

The rate of degradation of polyurethanes in hydrolytic conditions was slow. After 36 weeks of incubation in the buffer solution, the samples reduced their weight to 4.9 and $8.9 \%$, respectively, for PUR 10 and PUR 30. As it was expected PUR 30 (with the higher amount of linear, almost amorphous R,S-PHB), with lower density and higher water sorption, degraded faster.

What is interesting the weight reduction of cross-linked PUR 10 was higher than linear polyurethane with similar construction of soft segments (but with $\mathrm{PCL}_{\text {diol }}$ instead of $\mathrm{PCL}_{\text {triol }}$ ) under hydrolytic conditions of phosphate buffer solution (Brzeska et al. 2015c). Decreased molecular mass of linear polyurethanes after 36 weeks incubation in buffer
Table 3 Thermal properties of polyurethanes and their blends with PDLLA before and after incubation in hydrolytic (PBS) and oxidative $(\mathrm{OX})$ solutions

\begin{tabular}{lccccccc}
\hline Sample & $\begin{array}{l}\text { Incubation time } \\
\text { (weeks) }\end{array}$ & $\begin{array}{l}T_{\mathrm{m} 1} \\
\left({ }^{\circ} \mathrm{C}\right)\end{array}$ & $\begin{array}{c}\Delta H_{1} \\
(\mathrm{~J} / \mathrm{g})\end{array}$ & $\begin{array}{c}T_{\mathrm{m} 2} \\
\left({ }^{\circ} \mathrm{C}\right)\end{array}$ & $\begin{array}{l}\Delta H_{2} \\
(\mathrm{~J} / \mathrm{g})\end{array}$ & $\begin{array}{l}T_{\mathrm{m} 3} \\
\left({ }^{\circ} \mathrm{C}\right)\end{array}$ & $\begin{array}{l}\Delta H_{3} \\
(\mathrm{~J} / \mathrm{g})\end{array}$ \\
\hline PUR 10 & $0^{*}$ & 54.2 & 9.1 & 88.1 & 1.8 & 121.4 & 0.60 \\
PUR 10 (PBS) & 12 & 57.6 & 7.5 & 97.4 & 5.9 & - & - \\
& $36^{*}$ & 60.6 & 12.3 & 99.0 & 5.3 & - & - \\
PUR 10 (OX) & 12 & 59.3 & 15.5 & - & - & 120.2 & 0.20 \\
& $16^{*}$ & 56.9 & 14.5 & - & - & - & - \\
PUR 10/PDLLA & 0 & 51.9 & 18.6 & - & - & 121.9 & 0.01 \\
PUR 10/PDLLA (PBS) & 12 & 61.5 & 15.4 & - & - & 120.1 & 0.20 \\
& 36 & 58.1 & 18.7 & - & - & 124.7 & 0.01 \\
PUR 10/PDLLA (OX) & 12 & 72.5 & 23.0 & - & - & 120.2 & 0.07 \\
& 16 & 58.5 & 12.6 & - & - & 125.0 & 0.03 \\
PUR 30 & $0^{*}$ & 54.1 & 15.9 & 94.8 & 0.7 & - & - \\
PUR 30 (PBS) & 12 & 58.8 & 10.9 & 105.4 & 3.8 & - & - \\
PUR 30 (OX) & $36^{*}$ & 56.1 & 15.6 & 105.7 & 8.0 & - & - \\
& 12 & 61.3 & 12.9 & - & - & 119.9 & 0.30 \\
PUR 30/PDLLA & $16^{*}$ & 57.7 & 11.2 & - & - & 120.6 & 0.20 \\
PUR 30/PDLLA (PBS) & 12 & 54.7 & 19.2 & - & - & 125.2 & 0.02 \\
PUR 30/PDLLA (OX) & 12 & 64.0 & 11.7 & - & - & 120.5 & 0.10 \\
& 16 & 54.1 & 18.9 & - & - & 124.4 & 0.10 \\
& 36 & 61.7 & 9.0 & - & - & 120.2 & 0.06 \\
& 58.8 & 16.8 & - & - & - & - \\
\hline
\end{tabular}

* Data presented in (Brzeska et al. 2017) 

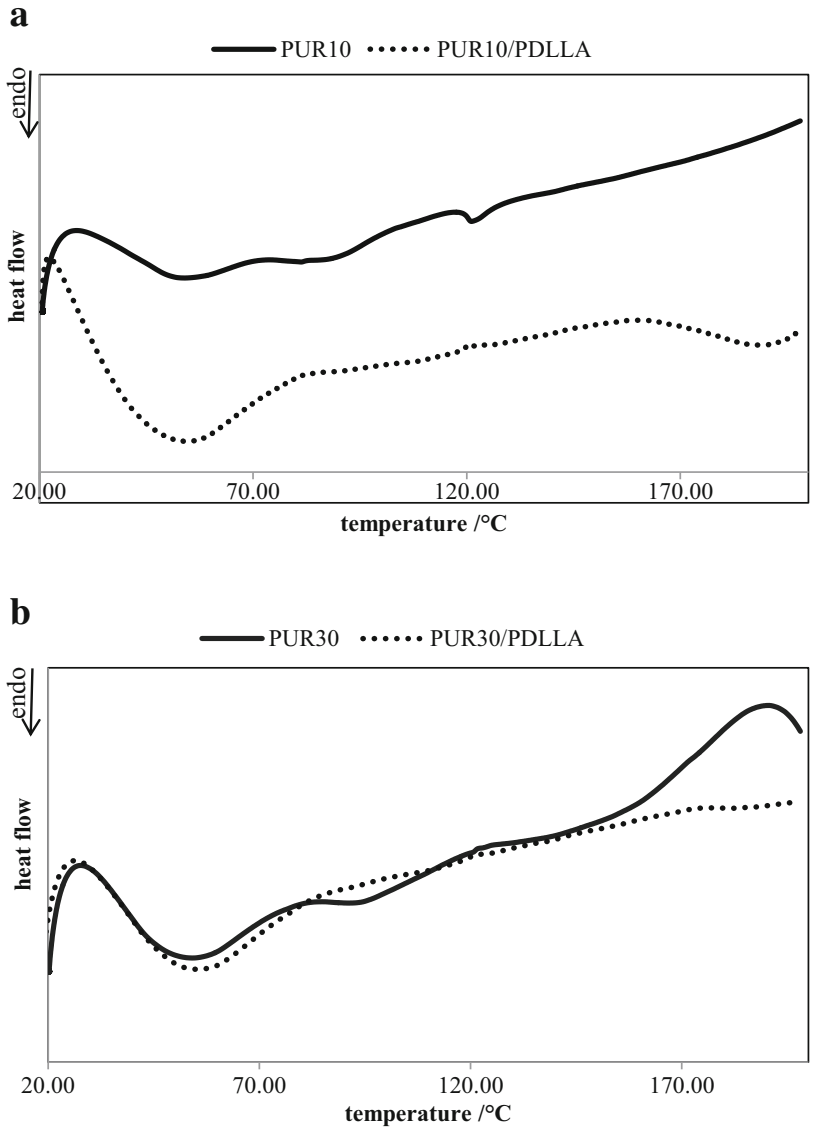

Fig. 4 DSC thermograms of polyurethanes PUR 10 (a) and PUR 30 (b), and their blends with PDLLA

solutions indicated that macrochains were cut but not eluted from polymer bulk at this stage of degradation (Brzeska et al. 2015c).

As it was also expected, polyurethanes degradation under hydrolytic conditions was accelerated after blending with PDLLA. The changes were similar as in case of blends of linear polyurethanes (Brzeska et al. 2015c).

According to results of studies conducted by Christenson (Christenson et al. 2004) treatment with $20 \%$ hydrogen peroxide $/ 0.1 \mathrm{M}$ cobalt chloride solution at $37{ }^{\circ} \mathrm{C}$ reproduced the chemical and physical characteristics of in vivo degradation at an accelerated rate. So time of polyurethane samples incubation in oxidative solution was shorter (16 weeks) than in phosphate buffer solution (36 weeks). Despite that high reactivity of oxidative solution, the samples weight reduction at the end of investigation was small. So, it could be stated that polyurethanes and their composites with polylactide degraded faster in hydrolytic than in oxidative solution (Fig. 2). It indicated that the degradation process run mainly by hydrolysis of ester groups.

Polyurethanes and their blends with polylactide degraded in the oxidative solution slower than in hydrolytic conditions. It is well known that ester linkages are sensitive to hydrolytic attack, whereas other linkages are sensitive to oxidative agents. It was the reason why the investigated polyurethanes (with oligoesters in soft segments) and their blends (with ester linkages in the structure) degraded faster in the phosphate buffer than in the oxidative solution.

Introducing of $\mathrm{PCL}_{\text {triol }}$ into soft segments of polyurethanes moved its melting temperature $\left(T_{\mathrm{m} 1}\right)$ from 40.7 to about $54{ }^{\circ} \mathrm{C}$ and reduced the melting enthalpy $\left(\Delta H_{1}\right)$ from $34.7 \mathrm{~J} / \mathrm{g}$ to 9.1 and $15.9 \mathrm{~J} / \mathrm{g}$, respectively, for PUR 10 and PUR 30 (Table 3). The addition of more R,S-PHB into PUR 30 than into PUR 10 increased the mobility of $\mathrm{PCL}_{\text {triol }}$ chains and their ordering what consequently increased their crystallinity (despite the amorphous state of R,S-PHB).

Blending the cross-linked polyurethane PUR 10 with PDLLA decreased the melting temperature of its soft segments. Chains of polylactide acted as plasticizers which caused reduction of the melting temperature (Fig. 4a). This was not observed for the sample with the higher amount of R,S-PHB (PUR 30), wherein blending the polyurethane with polylactide shifted slightly $\mathrm{Tm}_{1}$ to higher temperature on DSC thermograms (Fig. 4b).

In both cases, for PUR 10 and PUR 30, the presence of chains of amorphous polylactide visibly facilitated the ordering of polyurethane chains, which consequently caused an increase of soft segment crystallinity (increasing of $\left.\Delta H_{1}\right)$.

Increasing of R,S-PHB content in soft segments caused the greater distances between the cross-links network nodes (the amount of $\mathrm{PCL}_{\text {triol }}$ was reduced) and between the polyurethane chains (because of side methyl groups in R,SPHB). This increased free space between the chains and plasticizing action of polylactide facilitated the water molecules penetration into the network of polyurethanes, despite the increase in crystallinity of PUR 30 and blends in comparison to PUR 10. It resulted in increasing of the amount of absorbed water by polyurethanes and their blends (Fig. 1).

After incubation of polyurethanes and their blends in both degradative environments, an increase in the melting temperature of soft segments was observed. It suggested that polyurethane macrochains were additionally crosslinked. Tendency of degraded polymers to further crosslink was especially visible during incubation in the oxidative solution, what caused the swelling of samples (Fig. 3).

Two processes were observed in soft segment structure after the incubation of samples in degradative solutions: (1) increasing of $\Delta \mathrm{H}_{1}$ what suggested that amorphous phase degraded first (it caused that amount of crystalline phase increased) and (2) decreasing $\Delta H_{1}$ suggested that short polymer chains, created after degradation, were reorganized and cross-linked. 
Table 4 The surface of polyurethanes and their composites at AFM-phase image $(5 \times 5 \mu \mathrm{m}$ for samples of PUR $30 /$ PDLLA and $3 \times 3 \mu \mathrm{m}$ for other samples) before and after incubation in hydrolytic (36 weeks) and oxidative (16 weeks) solutions

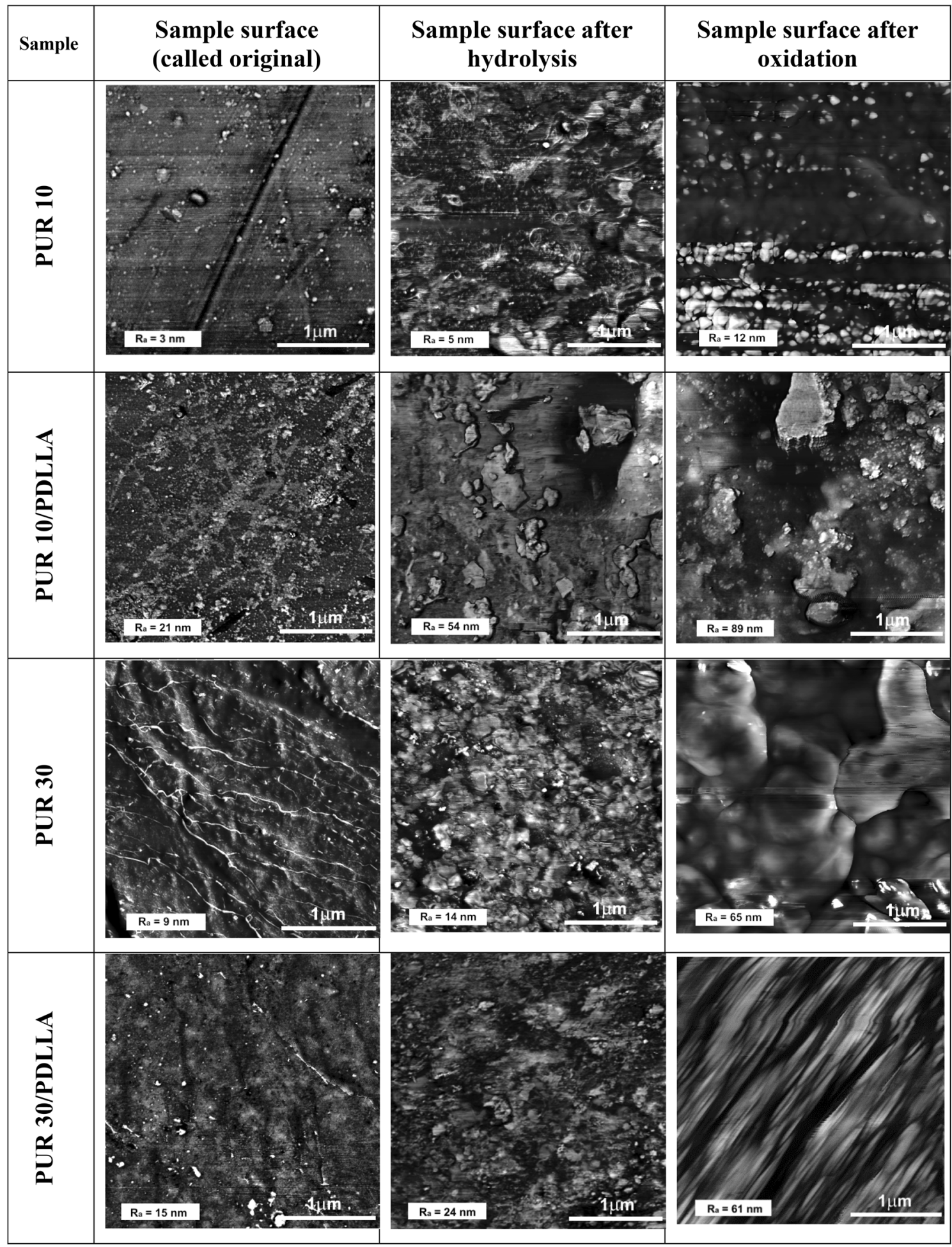

Table 4 shows AFM analysis of the microtopography of the polyurethanes and their blends with PDLLA before and after their incubation in oxidative and hydrolytic solutions. The average roughness $\left(R_{\mathrm{a}}\right)$ of polymer surface was immersed in lower left corner of each picture.
Generally, the surface of native samples was quite smooth. The fact that the roughness of all samples surface was higher than for PUR $10\left(R_{\mathrm{a}}=3 \mathrm{~nm}\right)$ could be associated with their higher crystallinity (Table 3 ). Increasing of R,S-PHB content in soft segments increased surface 
roughness from 3 to $9 \mathrm{~nm}$, respectively, for PUR10 and PUR30. Also blending of polyurethanes with PDLLA had made their surface more rough.

AFM analysis confirmed that surfaces of PURs and their blends after incubation in hydrolytic and oxidative solutions became much rougher. It is known that degradation begins with the penetration of water into the polymer structure. In case of PDLLA and polyesterurethanes, it leads to hydrolysis of esters bonds primarily in the amorphous phase (Nowak and Pajak 2010). The short water-soluble polymer chains are formed and moved into the surrounding environment. When the rate of release of these oligomers is higher than the speed of water diffusion into the sample bulk, the surface erosion is visible (Nowak and Pajak 2010).

AFM-phase images showed that the surface of degraded samples was eroded (Table 4). The depth of depressions on the surface of the samples was much higher after their incubation in degradative solutions than before. Changes in surface roughness were significantly higher after incubation in aggressive oxidative than in hydrolytic solution.

Despite that the weight loss of degraded samples was not significant (Figs. 2, 3) the changes of thermal properties of polymers and changes of the surface topography indicated that cross-linked polyurethanes, based on synthetic poly([R,S]-3-hydroxybutyrate), and their blends with poly $([\mathrm{D}, \mathrm{L}]-$-lactide $)$ were susceptible to degradation.

\section{Conclusions}

Cross-linked polyurethanes based on synthetic poly $([R, S]-$ 3-hydroxybutyrate) and their blends with poly([D,L]-lactide) appeared as degradable under hydrolytic and oxidative solutions. Because of very aggressive conditions of the oxidative solution, it was stated that polyurethanes degraded mainly through the hydrolysis. Increasing R,S-PHB amount in soft segments and blending polyurethanes with PDLLA introduced more ester linkages (sensitive to hydrolytic degradation) and increased the distance between the network nodes in cross-linked polyurethanes. It was the main reason of higher water sorption, and thus, higher degradability of polyurethane PUR 30 than PUR 10, and also blends with PDLLA than native PURs. Despite of small mass reduction of polyurethanes and their blends after incubation in degradative solutions, changes of thermal properties and surface erosion were observed.

Open Access This article is distributed under the terms of the Creative Commons Attribution 4.0 International License (http://crea tivecommons.org/licenses/by/4.0/), which permits unrestricted use, distribution, and reproduction in any medium, provided you give appropriate credit to the original author(s) and the source, provide a link to the Creative Commons license, and indicate if changes were made.

\section{References}

Aranguren MI, Marcovich NE, Mosiewicki MA (2015) Mechanical performance of polyurethane (PU)-based biocomposites. In: Pandey JK, Mohanty A (eds) Misra M. Biocomposites design and mechanical performance. Elsevier Ltd., Cambridge, Waltham, Kidlington. doi:10.1016/B978-1-78242-373-7.00010-X

Arniza MZ, Hoong SS, Idris Z, Yeong SK, Hassan HA, Din AK, Choo YM (2015) Synthesis of transesterified palm olein-based polyol and rigid polyurethanes from this polyol. J Am Oil Chem Soc 92:243-255. doi:10.1007/s11746-015-2592-9

Arslan H, Adamus G, Hazer B, Kowalczuk M (1999) Electrospray ionisation tandem mass spectrometry of poly [(R, S)-3-hydroxybutanoic acid] telechelics containing primary hydroxy end groups. Rapid Commun Mass Sp 13:2433-2438

Brzeska J, Heimowska A, Morawska M, Niepsuj A, Sikorska W, Kowalczuk M, Rutkowska M (2015a) Composites of polyurethanes based on poly([R,S]-3-hydroxybutyrate) with chitosan (in Polish). Polimery 60(6):391-395. doi:10.14314/polimery. 2015.391

Brzeska J, Janeczek H, Janik H, Kowalczuk M, Rutkowska M (2015b) Degradability in vitro of polyurethanes based on synthetic atactic poly[(R, S)-3-hydroxybutyrate]. Bio-Med Mat Eng 25:117-125. doi:10.3233/BME-151262

Brzeska J, Heimowska A, Sikorska W, Jasińska-Walc L, Kowalczuk M, Rutkowska M (2015c) Chemical and enzymatic hydrolysis of polyurethane/polylactide blends. Int J Polym Sci 2015:1-8. doi: $10.1155 / 2015 / 795985$

Brzeska J, Morawska M, Sikorska W, Kowalczuk M, Rutkowska M (2016) Degradation of cross-linked polyurethanes blended with polylactide (in Polish). In: Proceedings of pomerania-plast. Międzyzdroje, Poland, 147-148

Brzeska J, Morawska M, Heimowska A, Sikorska W, Tercjak A, Kowalczuk M, Rutkowska M (2017) Degradability of crosslinked polyurethanes/chitosan composites. Polimery 62(7-8):771-779. doi:10.14314/polimery.2017.771

Christenson EM, Anderson JM, Hiltner A (2004) Oxidative mechanisms of poly(carbonate urethane) and poly(ether urethane) biodegradation: in vivo and in vitro correlations. J Biomed Mat Res Part A 70A(2):245-255. doi:10.1002/jbm.a.30067/full

Datta J, Głowińska E (2014) Effect of hydroxylated soybean oil and bio-based propanediol on the structure and thermal properties of synthesized bio-polyurethanes. Ind Crops Prod 61:84-91. doi:10. 1016/j.indcrop.2014.06.050

Feng Y, Li C (2006) Study on oxidative degradation behaviors of polyesterurethane network. Polym Deg Stab 91:1711-1716. doi:10.1016/j.polymdegradstab.2005.12.002

Glarner M, Gogolewski S (2007) Degradation and calcification in vitro of new bioresorbable terpolymers of lactides with an improved degradation pattern. Polym Deg Stab 92(2):310-316. doi:10.1016/j.polymdegradstab.2006.10.009

Grzesiak J, Marycz K, Szarek D, Bednarz P, Laska J (2015) Polyurethane/polylactide-based biomaterials combined with rat olfactory bulb-derived glial cells and adipose-derived mesenchymal stromal cells for neural regenerative medicine applications. Mat Sci Eng C 52:163-170. doi:10.1016/j.msec.2015.03.050

Gurunathan T, Mohanty S, Nayak SK (2014) Preparation and performance evaluation of castor oil-based polyurethane prepolymer/polylactide blends. J Mat Sci 49:8016-8030. doi:10. 1007/2Fs10853-014-8509-4

Imre B, Bedő D, Domján A, Schön P, Vancso GJ, Pukánszky B (2013) Structure, properties and interfacial interactions in poly(lactic acid)/polyurethane blends prepared by reactive processing. Eur Polym J 49:3104-3113. doi:10.1016/j.eurpo lymj.2013.07.007 
Ionescu M, Radojčić D, Wan X, Shrestha ML, Petrović ZS, Upshaw TA (2016) Highly functional polyols from castor oil for rigid polyurethanes. Eur Polym J 84:736-749. doi:10.1016/j.eurpo lymj.2016.06.006

Jašo V, Glenn G, Klamczynski A, Petrović ZS (2015) Biodegradability study of polylactic acid/thermoplastic polyurethane blends. Polym Test 47:1-3. doi:10.1016/j.polymertesting.2015. 07.011

Jing X, Mi H-Y, Peng X-F, Turng L-S (2015) The morphology, properties, and shape memory behavior of polylactic acid/ thermoplastic polyurethane blends. Polym Eng Sci 55(1):70-80. doi:10.1002/pen.23873

Martínez-Abad A, González-Ausejo J, Lagarón JM, Cabedo L (2016) Biodegradable poly(3-hydroxybutyrate-co-3-hydroxyvalerate)/ thermoplastic polyurethane blends with improved mechanical and barrier performance. Pol Deg Stab 132:52-61. doi:10.1016/j. polymdegradstab.2016.03.039

Nampoothiri KM, Nair NR, John RP (2010) An overview of the recent developments in polylactide (PLA) research. Bioresour Technol 101:8493-8501. doi:10.1016/j.biortech.2010.05.092

Nowak B, Pająk J (2010) Biodegradation of poly(lactide) (PLA) (in Polish). Arch Waste Manag Env Prot 12(2):1-10

Okoli CP, Adewuyi GO, Zhang Q, Diagboya PN, Guo Q (2014) Mechanism of dialkyl phthalates removal from aqueous solution using $\gamma$-cyclodextrin and starch based polyurethane polymer adsorbents. Carbohyd Polym 114:440-449. doi:10.1016/j.carb pol.2014.08.016

Raquez J-M, Habibi Y, Murariu M, Dubois P (2013) Polylactide (PLA)-based nanocomposites. Prog Polym Sci 38:1504-1542. doi:10.1016/j.progpolymsci.2013.05.014

Saini P, Arora M, Kumar MNVR (2016) Poly(lactic acid) blends in biomedical applications. Adv Drug Deliv Rev 107:47-59. doi:10.1016/j.addr.2016.06.014

Saralegi A, Gonzalez ML, Valea A, Eceiza A, Corcuera MA (2014) The role of cellulose nanocrystals in the improvement of the shape-memory properties of castor oil-based segmented thermoplastic polyurethanes. Com Sci Tech 92:27-33. doi:10.1016/j. compscitech.2013.12.001
Silva EABd, Zabkova M, Araújo JD, Cateto CA, Barreiro MF, Belgacem MN, Rodrigues AE (2009) An integrated process to produce vanillin and lignin-based polyurethanes from Kraft lignin. Chem Eng Res Des 87:1276-1292. doi:10.1016/j.cherd. 2009.05.008

Szelest-Lewandowska A, Skupień A, Masiulanis B (2002) Synthesis and properties of new polyurethanes for medicine (in Polish). Elastomery 6(6):3-14

Vert M (2015) After soft tissues, bone, drug delivery and packaging, PLA aims at blood. Eur Pol J 68:516-525. doi:10.1016/j. eurpolymj.2015.03.051

Yu F, Huang H-X (2015) Simultaneously toughening and reinforcing poly(lactic acid)/thermoplastic polyurethane blend via enhancing interfacial adhesion by hydrophobic silica nanoparticles. Polym Test 45:107-113. doi:10.1016/j.polymertesting.2015.06.001

Zhang L, Xiong Z, Shams SS, Yu R, Huang J, Zhang R, Zhu J (2015) Free radical competitions in polylactide/bio-based thermoplastic polyurethane/free radical initiator ternary blends and their final properties. Polymer 64:69-75. doi:10.1016/j.polymer.2015.03. 032

Zhang T, Kong L, Dai Y, Yue X, Rong J, Qiu F, Pan J (2017) Enhanced oils and organic solvents absorption by polyurethane foams composites modified with $\mathrm{MnO}_{2}$ nanowires. Chem Eng J 309:7-14. doi:10.1016/j.cej.2016.08.085

Zia F, Zia KM, Zuber M, Ahmad HB, Muneer M (2016a) Glucomannan based polyurethanes: a critical short review of recent advances and future perspectives. Int J Biol Macromol 87:229-236. doi:10.1016/j.ijbiomac.2016.02.058

Zia F, Zia KM, Zuber M, Rehman S, Tabasum S, Sultana S (2016b) Synthesis and characterization of chitosan/curcumin blends based polyurethanes. Int J Biol Macromol 92:1074-1081. doi:10.1016/j.ijbiomac.2016.08.005

Zuber M, Zia F, Zia KM, Tabasum S, Salman M, Sultan N (2015) Collagen based polyurethanes - a review of recent advances and perspective. Int J Biol Macromol 80:366-374. doi:10.1016/j. ijbiomac.2015.07.001 